DOI 10.37882/2500-3682.2021.05.23

\title{
ФИЛОСОФСКИЕ И ЕСТЕСТВЕННОНАУЧНЫЕ АСПЕКТЫ В КОНТЕКСТЕ АНАЛИЗА И ПОИСКА КРИТЕРИЕВ ОПРЕДЕЛЕНИЯ КАТЕГОРИИ ОБЪЕКТ - ТЕЛО
}

\section{PHILOSOPHICAL AND NATURAL SCIENCE ASPECTS IN THE CONTEXT OF ANALYSIS AND SEARCH FOR CRITERIA FOR DETERMINING THE OBJECT - BODY CATEGORY}

\section{Rychansky}

I. Berezkina

Summary: The article is devoted to the development of the philosophical category of the object-the body. The author formulates the criteria by which it is possible to define an object as a «body». It also provides a brief analysis of current philosophical studies of the phenomenon of the body, as a result of which the author comes to the conclusion that the phenomenon of the body in modern philosophical discourse is considered in the context of various aspects. In this analysis, the author uses the most relevant works of modern philosophers and scientists. However, in this article, the body is considered primarily as a physical object belonging to the empirical world, and therefore the issues related to the possibility of a reliable definition of the body as a physical object are updated. The author supports his conclusions about the possibility of defining clear criteria for determining the object «body» with arguments and concrete examples. This article may have theoretical and practical significance for specialists both in the field of natural science and for scientific research in the context of the problems inherent in humanitarian research. This article may also be useful for a wide range of readers interested in scientific problems in the study of the body as a physical object.

Keywords: matter, existence, man, object, single, single object, object many, body, object - body.

\author{
Рычанский Дмитрий Анатольевич \\ стариий бухгалтер, ООО «Проектно-строительная \\ компания», г. Белгород \\ dimarichy@yandex.ru \\ Берёзкина Илеанора Владимировна \\ учитель физики и информатики, МБОУ СОШ №36, \\ г. Белгород
}

Аннотация: Статья посвящена разработке философской категории объекта тело. Автор формулирует критерии, благодаря которым возможно определить тот или иной объект как «тело». А также дается краткий анализ актуальных философских исследований феномена тела, в результате которого автор приходит к выводу о том, что феномен тела в современном философском дискурсе рассматривается в контексте различных аспектов. В данном анализе автором используются наиболее актуальные труды современных философов и ученых. Однако в данной статье тело рассматривается, прежде всего, как физический объект, принадлежащий кэмпирическому миру, а потому актуализируются вопросы, связанные с возможностью достоверного определения тела как физического объекта. Свои выводы касательно возможности определения четких критериев при определении объекта «тело» автор подкрепляет аргументами и конкретными примерами. Данная статья может иметь теоретическую и практическую значимость для специалистов как в естественнонаучной сфере, так и для научных поисков в контексте проблематики, присущей гуманитарным исследованиям. Также данная статья может оказаться полезной для широкого круга читателей, интересующихся научной проблематикой в исследовании тела как физического объекта.

Ключевые слова: материя, бытие, человек, объект, единичное, единичный объект, объект множество, тело, объект - тело.
$\Pi$ роблема телесности в истории философии является одним из мотивов, определяющих сам стиль философского мышления. Теоретическая эволюция западной метафизики неотделимы от апелляции к телесности. Следовательно, в связи с этим понятием, в отношении него, находит отражение сама суть того или иного философского направления. Разделение понятий «тело» и «телесность», особенно в социальной философии, является чрезвычайно сложной проблемой. Это связано, во-первых, с «естественной очевидностью» тела, на которое, сознательно или нет, возлагается большинство исследователей, пытаясь анализировать этот феномен, а во-вторых - с традиционной оппозицией естественных и гуманитарных наук в стратегиях исследования природы человека и такого объекта как тело.
В повседневной речи понятие «тело» и «телесность» употребляются, как правило, синонимично. Философия имеет среди наук исключительное право «особого» использования языка и традиционно достаточно свободно пользуется большим количеством «обычных» аналогий. Это связано с тем, что именно в философском дискурсе происходит формирование понятий и создание адекватной основы понимания явлений и терминологического аппарата их исследования, изучаются критерии и пределы применения понятий в широком контексте. Сегодня философская проблема телесности, как неотъемлемого атрибута природы человека, достигла такого уровня развития и разнообразия толкований, что требует глубокой разработки и концептуализации. 
Среди исторических этапов в формировании современного отношения к категориям «тело» и «телесность» важны во-первых, исследования Декарта [7] и проблематика «психофизического дуализма», а, во-вторых, отношение к телу в философии жизни Ницше [11], в-третьих, рождение и развитие философского понятия «телесности» в феноменологии Гуссерля [8], Сартра [15], МерлоПонти [10], Шюца [17], и, наконец - взгляд современной социальной топологии Фуко [16], Делеза [6], Бурдье [4] о роли тела человека в социальном пространстве.

Понятие «тело» - средоточие указанной проблематики - имеет огромное количество экспликаций во всех сферах человеческой жизни: от повседневности - к религиозным практикам, от медицины - к искусству, от личных отношений - к социальным ролям.

В широком смысле «тело» - это материальная вещь (объект эмпирического мира - физическое тело), предмет. «Тело, погружаемое в жидкость, выталкивает объем жидкости равный своему...». Это первое, что приходит в голову, когда речь заходит о научном понимании тела. Великий мыслитель древности Аристотель оставил нам богатое наследие в математике, геометрии, физике в отношении такого предмета как тело. Он научил нас, что именно нам делать с телом, как его помещать в жидкость, сколько при этом газа оно выталкивает и что нам делать, что бы оно ни утонуло.

Что же мы имеем в философии на этот счет?

Тело - понятие философского дискурса, характеризующее

1. физически ограниченную часть вещественной материи, устойчивый комплекс качеств, сил и энергий,

2. живой организм в его соотнесенности или сопряженности с душой. Уже в античной философии проведено различие между $\sigma \alpha \rho \xi$ и $\sigma \tilde{\omega} \mu \alpha$, между физическим телом и одушевленным телом.

В физике, как естественной науке, тело воспринимается как конкретный объект. Отсюда и приходит к нам наделение этого термина массой характеристик и параметров:

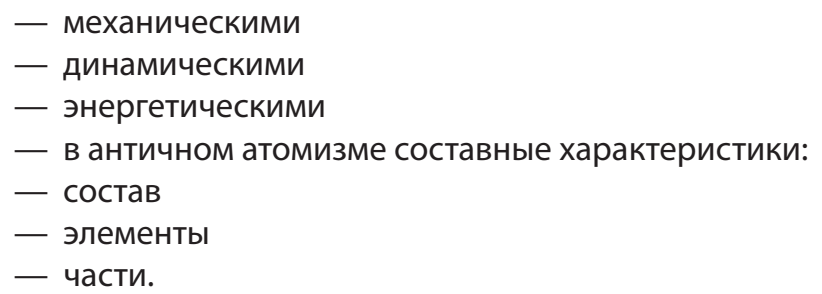

Все это обусловлено тем, что в физике тело является участником процессов, следовательно, решая задачи физики, все вышеперечисленные характеристики становятся необходимы. Тела обладают формой, состоят из субстанции, наделены жизнью или нет. Обладают протяженностью во все стороны и делимы во всех измерениях. В развитии термин «тело» следовал за развитием естественный наук.

Целью данной работы является разработка философского термина «тело», изначально определяя его как материальный объект.

Первое на что обратим свое внимание - это то, что термин тело используется и как часть любой вещественной материи - камень, мяч, топор, молекула воды и прочее, так и как живой организм человек, паук, лягушка. Причем дерево уже спорный объект, с одной стороны оно растет, питается, плодоносит, с другой стороны оно всех больше интересует как строительный материал, то есть когда уже погибло - ни растет, ни питается, ни плодоносит, но еще существует. Эта разница очевидна, когда мы произносим этот термин просто как слово, но есть ли в ней смысл с точки зрения философии?

Если мы предметно рассматриваем неживые предметы, мы обычно говорим об их размерах, массе, плотности, если же мы говорим о человеке, то эти категории тоже приемлемы, но при этом мы понимаем насколько скудно, они характеризуют его. Организм - объект намного сложнее. Но судить о нем как о теле все равно можно. Следовательно, нам необходимо оставить только те характеристики тела, которые подходят в обоих случаях.

По нашей ранее принятой методике введем понятия объект и граница. Простое восприятие тела происходит визуально. Что мы видим, разглядывая любой предмет? Обычно мы видим его границы, можем определить его размеры, выделить у предмета некоторые детали. Такими характеристиками обладают все воспринимаемые на глаз объекты. Но если они у всех предметов одинаковые, то почему мы знаем, что они (предметы) разные? Как мы их узнаем? Как мы узнаем, что это именно они? Потому, что они разные по форме, по размеру - они имеют пространственные границы. А что есть эти самые пространственные границы? Ответив на этот вопрос, мы поймем и сам феномен пространство.

В предыдущих наших работах, мы определились материальным объектом считать часть материи, имеющей внешние границы. Допустим, что внешние границы объекта и есть пространственные границы объекта. Но что именно мы воспринимаем, когда видим их? А видим мы в них то, что они не совпадают между собой! Именно поэтому мы их и видим. По тому, как эти границы не совпадают мы и определяем объект, как его форму, так и его размеры.

Объект «тело» - это объект, внешние границы кото- 
рого не совпадают между собой. Степень «не совпадения» границ порождает феномен протяженность. Вот и ускользающий феномен «пространство» обретает свои законные границы. Пространство - это место в материи, которое занимает тело.

Но почему это настолько не очевидно, пространство есть суть граница тела? На наш взгляд, потому что, когда мы говорим о теле предмета, мы имеем ввиду конкретный объект, который зачастую нас интересует: колбаса, сыр, автомобиль, одежда, дом. А когда в том месте материи, куда мы обращаем наше внимание, нет интересующих нас объектов, мы подразумеваем пространство: безвоздушное пространство, пространственная речь, пустое ведро - что в нем? пространство (в нем конечно есть воздух, но для того чтобы утолить жажду нам нужна вода). То есть, говоря о теле, мы подразумеваем наличие предмета, если речь о пространстве мы подразумеваем пустоту - отсутствие интересующего нас объекта.

Попробуем привести обратный пример. Допустим, мы направляемся из точки «А» в точку «Б». Точка «Б» место материи, которое нас интересует. Границы точки совпадают между собой, она не имеет протяженности. Следовательно, точка «Б» есть объект единичное, и не является объектом тело. Дорога из точки «А» в точку «Б» проходит вдоль прямой, образуя отрезок «АБ», добавив объект множество, определим его протяженность в пять километров. Отрезок «АБ» не совпадает между своими пространственными границами вдоль прямой на которой он находиться, на пять километров, но рассматривая его перпендикулярно, параллельно земле его границы совпадают, то есть протяженности не имеют. Следовательно, отрезок имея пространственные границы телом еще не стал. Уста- новим, что точки «А» и «Б» соединяет дорога, имеющая ширину полотна три метра. Таким образом, получается, что дорога не совпадает в своих границах на пять километров в длину и три метра в ширину, образуя вытянутый прямоугольник на плоскости. Стала ли дорога телом? Нет. Так как, взглянув на нее перпендикулярно, по высоте она совпадает в границах с плоскостью образованного ранее прямоугольника. Но если мы представим, что наша дорога уложена тротуарной плиткой высотой шесть сантиметров, то мы получим участок дорожного полотна длинной пять километров, шириной три метра и высотой шесть сантиметров. Теперь наш объект имеет границы, не совпадающие во всех направлениях, и он превратился в объект тело. Выполнив необходимый расчет 5000 X 3 X 0,06 установим, что для покрытия пешеходной дорожки на этом участке нам потребуется 900 кубических метров тротуарной плитки, а это уже термин характеризующий объем тела. Если из этого объема извлечь всю плитку, то получится пространство между точками «А» и «Б» общим объемом 900 метров кубических.

\section{Зак^ючение}

Таким образом, в историко-философском дискурсе феномен тела рассматривается в контексте его различных аспектов. То есть данный объект исследования изучается не только как физический объект, но и как объект социальный. Однако для нашего исследования ключевым является естественнонаучный аспект данного вопроса, то есть тело мы анализировали исключительно как объект эмпирического мира, а потому уточним сформулированное выше определение: объект тело - это объект, внешние границы которого не совпадают между собой во всех направлениях.

\section{ЛИТЕРАТУРА}

1. Аристотель. Соч.: В 4 т. Т. 1. с. 550.

2. Ананьев Б.Г. Человек как предмет познания. М.: Наука, 2000. -351 с.

3. Бердяев Н. Человек и машина. (Проблема социологии и метафизики техники). - М.: Путь. -Май 1933.

4. Бурдье П. Физическое и социальное пространства / П.Бурдье «Социология социального пространства», СПб.: Алетейя, 2007. - 288 с.

5. Быховская, И.М. Физическая культура как практическая аксиология человеческого тела: методологические основания анализа проблемы. [Электронный ресурс]. - Режим доступа: http://www.infosport.ru/press/fkvot/ 1996N2/p19-27.htm.

6. Декарт, Рене. Из переписки 1663-1649 гг. // Сочинения: В 2 т - М.: Мысль, 1989,- Т. 2 - С. 490.

7. Делёз Ж., Гваттари Ф. Тысяча плато. Капитализм и шизофрения / Пер. с фр. и послесл. Я.И. Свирского, науч. ред. В.Ю. Кузнецов. Екатеринбург; М., 2010

8. Гуссерль Э. Избранные работы / Сост. В.А. Куренной. М.: Издательский дом «Территория будущего», 2005. - 464 с.

9. Кантор Г. Труды по теории множеств. - Москва, 1985. с. 431.

10. Мерло-Понти М. Феноменология восприятия / М. Мерло-Понти. - СПб. : Ювента; Наука, 1999. - 608 с.

11. Ницше. Так говорил Заратустра / перевод Д. Борзаковского, под ред. Арс. Введенского и Васильева. — М.: Издание М. В. Клюкина, 1900. — Т. І.

12. Рычанский Д.А. Единое и многое // Интернаука, 2018, №3(7). С. 68.

13. Рычанский Д.А., Берёзкина И.В. Единичный объект при анализе материи. Интернаука: научный журнал. № 4(86). Часть 2. - М., 2019. с. 64.

14. Рычанский Д.А., Берёзкина И.В. Множество как объект // Интернаука: научный журнал. № 3(132). Часть 1. - М., 2020. с. 92.

15. Сартр Ж.-П. Бытие и ничто. М.: Республика, 2000. 
16. Фуко М. Рождение биополитики / ФукоМ. -СПб.: Наука, 2010. -448с.

17. Шюц А. Размышления о проблеме релевантности, Глава 7: Биографическая ситуация / Шюц А. Избранное: Мир светящийся смыслом / Пер. С нем. и англ. - М.: «Российская политическая энциклопедия» (РОССПЭН), 2004.- 1056 с.

( Рычанский Дмитрий Анатольевич (dimarichy@yandex.ru), Берёзкина Илеанора Владимировна.

Журнал «Современная наука: актуальные проблемы теории и практики»

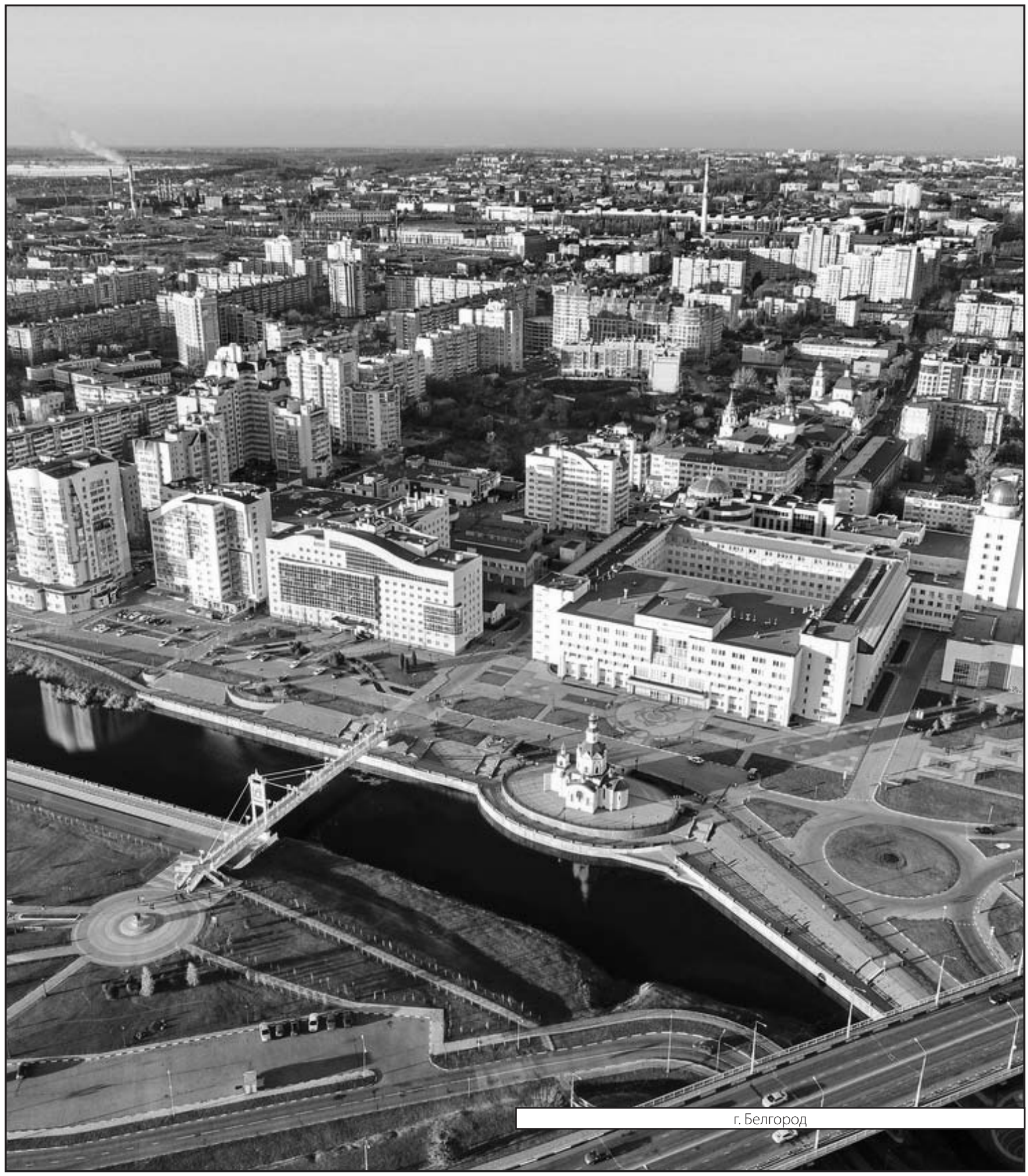

